\title{
Using cone beam CT to assess the upper airway after surgery in children with sleep disordered breathing symptoms and maxillary-mandibular disproportions: a clinical pilot
}

Noura A. Alsufyani ${ }^{1,5,6^{*}}$, Michelle L. Noga ${ }^{2}$, Manisha Witmans ${ }^{1}$, Irene Cheng ${ }^{3}$, Hamdy El-Hakim ${ }^{4}$ and Paul W. Major ${ }^{1}$

\begin{abstract}
Background: The surgical excision of anatomic obstructions such as adenoids, palatine or lingual tonsils are commonly performed in children with sleep disordered breathing (SDB). Imaging studies measuring airway changes post-surgery in the SDB pediatric population are scarce, rarely addresses the nasal cavity, and are based on global measures (e.g. volume) that do not represent the complexity of the upper airway anatomy. The purpose of this pilot is to test the feasibility in using cone beam $C T(C B C T)$ to analyze the nasal and pharyngeal airway space postsurgery using meaningful methods of analyses, and correlating imaging findings with clinical outcomes in children with SDB symptoms and maxillary-mandibular disproportion.

Methods: Twelve non-syndromic children with SDB symptoms and jaw disproportions were evaluated by interdisciplinary airway team before and after upper airway surgery. CBCT and OSA-18 quality of life questionnaire pre and post-operatively were completed. Conventional and new airway variables were measured based on 3D models of the upper airways and correlated with OSA-18. Conventional measures include volume, surface area, and cross-sectional area. New airway measures include constriction and patency; point-based analyses.

Results: Eight females and four males were $8.8 \pm 2$ years with mean BMI of $18.7 \pm 3$. OSA-18 improved, median (lower quartile-upper quartile) from $64.2(54.7-79.5)$ to 37.6 (28.7-43) postoperatively, $p<0.001$. The median of all airway measures improved however with very wide range. Subjects with the smallest amounts of constriction relief and/or gain in airway patency presented with least improvement in OSA-18. New airway measures show strong correlation with changes in OSA-18 ( $\rho=0.44$ to 0.71$)$ whereas conventional measures showed very weak correlation ( $\rho=-0.04$ to 0.37 ).

Conclusions: Using point-based analyses, new airway measures better explained changes in clinical symptoms compared to conventional measures. Airway patency gained by at least 150\% and constriction relief by at least 15\% showed marked improvement in OSA-18 by $40-55 \%$, after surgery in the tested cohort.
\end{abstract}

Keywords: Adenoidectomy, Tonsillectomy, Treatment outcome, Cone-beam computed tomography

\footnotetext{
* Correspondence: alsufyan@ualberta.ca

${ }^{1}$ School of Dentistry, Faculty of Medicine and Dentistry, University of Alberta, Edmonton, Canada

${ }^{5}$ Edmonton Clinic Health Academy- School of Dentistry, 5th floor, 11405-87

AVE NW, Edmonton T6G 1C9, AB, Canada

Full list of author information is available at the end of the article
} 


\section{Background}

The role of anatomical obstruction (adenoid, tonsillar, and nasal turbinates hypertrophy, deviated septum, and tongue position) on orthodontic changes and abnormal craniofacial growth are of continuous interest in the otolaryngology and orthodontic literature [1-3]. Controversies exist regarding the aetiology of paediatric sleep disordered breathing (SDB), but most accept anatomical obstruction of the upper airway as the most common cause. Adenotonsillar hypertrophy is considered the most important anatomic cause of such constriction thus prompting the American Academy of Paediatrics' recommendation of adenotonsillectomy (AT) as first line of treatment [4]. However, AT is not as effective as previously thought with failure rates as high as $54 \%$ in high-risk groups or comorbidities [5-7]. Information on underlying pathophysiologic mechanisms leading to residual SDB are limited. Only one study quantified volumetric changes using MRI in the paediatric upper airway with OSA after AT in which an association between residual adenoid tissue and low success rate of AT by means of polysomnography was found [7].

With its low radiation dose relative to multi-detector $\mathrm{CT}$, cone beam CT (CBCT) provides insights to the anatomical anomalies found along the upper airway and craniofacial disproportions and has been used to measure anatomic airway changes with surgical and dental appliance treatment for adult SDB/OSA [8]. However, significant drawbacks were related to the questionable accuracy of the reconstructed upper airway $3 \mathrm{D}$ models, lack of clinical correlation with CBCT measurements, and the use of global non-specific airway measure such as volume, linear, and cross-sectional area measurements $[8,9]$. Unlike global measures, point-based analysis with color mapping better explained differences in 3D upper airway models generated from CBCT [10]. Prospective studies analyzing the upper airway, by means of CBCT, and correlating anatomical airway changes with surgical outcomes in the SDB pediatric population are lacking [8, 11]. The aim of this clinical pilot is twofold: to prospectively evaluate anatomical changes that occur in the upper airways before and after AT using 3D airway models from CBCT; and to evaluate whether changes in anatomical airway measures are reflected in the patient's quality of life in a cohort of children/adolescents presenting with jaw disproportions and SDB symptoms.

\section{Methods}

\section{Subjects}

This study was approved by the Health Research Ethics Board at the University of Alberta. Thirteen consecutive non-syndromic children-adolescents with SDB symptoms were recruited from the Interdisciplinary Airway Clinic (IARC), Department of Dentistry, University of
Alberta. This tertiary center receives referrals from dentists or orthodontists in which the main concern of the subjects is maxillary-mandibular jaw disproportions with potential secondary SDB symptoms. As such, not many subjects undergo surgery. Based on the interdisciplinary evaluation of orthodontist, paediatric respirologist/sleep medicine specialist, and otolaryngology surgeon, the subjects underwent nasal or pharyngeal surgery to remove anatomical obstructions. A validated Pediatric Sleep Questionnaire (PSQ-22) and overnight pulse oximetry can be used as screening tools to identify SDB when PSG is not feasible [12-14]. The diagnosis of SDB is based on the history of nocturnal symptoms for at least 12 months, physical examination, overnight pulse oximetry, and Pediatric Sleep Questionnaire (PSQ-22) [15]. All subjects completed PSQ-22 and OSA-18 quality of life questionnaires and underwent $\mathrm{CBCT}$ imaging, overnight pulse oximetry, awake nasoendoscopy \& laryngoscopy and sleep endoscopy simultaneous with surgery. OSA-18 questionnaire and CBCT imaging were also completed after surgery. The aim was to recall subjects by 6 months post-operatively to allow sufficient time for tissues to stabilize.

\section{CBCT imaging}

The scans were obtained using Next generation iCAT $^{\oplus}$ (Imaging Sciences International, Hatfield, PA) with $0.3 \mathrm{~mm}$ voxel, $4 \mathrm{~s}$ of exposure, $120 \mathrm{kVp}$, and $5 \mathrm{~mA}$. The field of view extended from the Nasion superiorly to the chin inferiorly, the tip of the nose anteriorly and the bodies of cervical vertebrae posteriorly. Acquisition of CBCT scans was based on orthodontic reasons where conventional radiography failed to provide adequate information (e.g. maxillary constriction, anteroposterior or vertical discrepancies in the maxilla or mandible, or asymmetry). These disproportions are believed to be contributing factors to the SDB symptoms in this cohort with the prospects of maxillary expansion or orthognathic surgeries in their longer treatment plan justifying the use of CBCT. The authors do not support the use of $\mathrm{CBCT}$ for the sole purpose of airway analysis.

\section{Upper airway analysis}

The upper airway region of interest (ROI) included the nasopharynx, oropharynx, and the nasal cavity (inferior and middle nasal meatus) and extends from the anterior nares to the level of anterior-inferior point of the body of the third cervical vertebra (C3), details in Additional file 1: Figure S1. The ROI was segmented and reconstructed into 3D model (ASCII STL format) using a semi-automatic program Segura $\odot$, developed and validated at the University of Alberta [10]. Using Mimics ${ }^{\circ}$ [Mimics 15.0, Materialise NV, Leuven, Belgium], presurgical (T1) and post-surgical (T2) CBCT image sets 
were registered for each subject based on a previously validated method using six anatomical landmarks [16]. The 3D airway models were then imported and registered onto the "fused" CBCT image volumes using 10point registration followed by global registration which fine-tunes the 10-point registration. The registered 3D

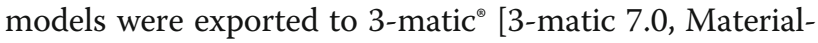
ise NV, Leuven, Belgium], smoothed by a factor of 0.7 and its surface wrapped. The upper airway was then divided into nasal cavity (NS), nasopharynx (NP), and oropharynx (OP) for further analysis using three planes, details are provided in Additional file 1: Figure S2. Airway measurements were carried out in 3 -matic $^{\circ}$ and consisted of:

1. Conventional measures, at $\mathrm{T} 1$ and $\mathrm{T} 2$ : Volume $\left(\mathrm{cm}^{3}\right)$ and surface area $\left(\mathrm{cm}^{2}\right)$ of NS, OP, and NP and Minimum cross-sectional area MinXarea $\left(\mathrm{mm}^{2}\right)$ in OP or NP, at T1 and T2. MinXarea in OP was identified manually as the smallest medio-lateral dimension on the coronal view, and in the NP as the smallest anterior posterior dimension on the sagittal view, followed by confirmation on the 3D model of the airway.

2. New measures, at $\mathrm{T} 1$ and $\mathrm{T} 2$ : airway constriction and patency of each segment at $\mathrm{T} 1$ and $\mathrm{T} 2$. These represent point-based analysis, referred to as "wall thickness analysis" in 3-matic. The software measures the distance of each triangular node, forming the 3D mesh of the airway model, to the nearest surface based on the normal vector of the triangle, details in Additional file 1: Figure S3. The resultant analysis provides minimum, maximum, mean, median, standard deviation, and interquartile range of all the distances travelled by all the triangles from one surface to the opposing. From a given histogram, the percentage of triangles that traveled a distance within a certain threshold set by the operator can be chosen. In this pilot, distances $<4 \mathrm{~mm}$ in the pharyngeal airway represent potential areas of constriction. Distances $>10 \mathrm{~mm}$ in pharyngeal airway were considered areas of patency. These cut-off numbers were estimations by expert radiologist based on the CBCT radiographic appearance of the pharyngeal airway

3. Part Comparison analysis of each segment, T2-T1: This tool was previously described $[10,16]$ and represents point-based analysis to assess the changes in 3D airway models between $\mathrm{T} 1$ and $\mathrm{T} 2$ to produce a color map. A threshold was set between 4 and $10 \mathrm{~mm}$ such that areas marked in green represent tissue changes $<4 \mathrm{~mm}$, orange-yellow represent changes between 4 and $10 \mathrm{~mm}$, and areas marked in red represent changes over $10 \mathrm{~mm}$, from $\mathrm{T} 1$ to $\mathrm{T} 2$.
Conventional and new airway variables are measures before and after surgery, i.e. at T1 and T2, whereas part comparison analysis provided the color map of $3 \mathrm{D}$ airway model at T2 subtracted from T1.

\section{Statistical analysis}

Statistical analysis was performed using IBM SPSS ${ }^{\bullet}$ [IBM SPSS Statistics 22.0, Armonk, NY]. Means ( \pm standard deviations) are reported for normally distributed variables. For non-parametric variables, median and quartile range marking $25 \%$ deviation on each side of the median were reported as: median (lower Q1- upper Q3 quartiles). For paired comparisons between $\mathrm{T} 1$ and $\mathrm{T} 2$ evaluations, Wilcoxon signed-rank test was used. To assess correlation between new and conventional airway measures with changes in OSA-18, Spearman Rho $(\rho)$ correlation coefficients were completed. $P$ value $<0.05$ was considered significant.

\section{Results}

Thirteen subjects were initially included in this pilot however one was excluded due to significant error in neck flexion and tongue positioning thus impacting the pharyngeal dimensions, where the subject received palatine tonsillectomy. The data of the remaining 12 was not normally distributed with few outliers, except for NS dimensions (normally distributed). Median (quartile range Q1-Q3) and other non-parametric tests were therefore used in this study, unless specified otherwise.

\section{Demographic/Clinical information}

The mean age of the 12 subjects, 8 female and 4 male, was $8.8 \pm 2$ years. The mean recall period was $7 \pm$ 1.5 months (range 4-9 months). Demographic, clinical, sleep naso-endoscopy, and type of surgery are summarized in Table 1 . Of the 12 , the mean BMI was $18.7 \pm 3$ (4 overweight or obese) and two had allergy and asthma. All subjects presented with short anterior cranial base, SellaNasion (SN) distance $=60.8 \pm 3.1 \mathrm{~mm}$ and ranged from 55.5 to $64.9 \mathrm{~mm}$. Seven (58.3\%) presented with "long face syndrome", three (25\%) with narrow maxilla-high arched palate, and two (16.6\%) with skeletal class III, i.e. prognathic mandible. At baseline, all subjects had sleep oximetry McGill score of 1 (i.e. normal or inconclusive of OSA) and mean PSQ-22 score of $0.50 \pm 0.17$. Nine (75\%) had monopolar suction diathermy adenoidectomy with/ without inferior turbinoplasty (microdebrider technique) and three $(25 \%)$ had microdebrider assisted tonsillectomy (2 lingual and 1 palatine) with supraglottoplasty (cold steel technique), completed by the same ENT surgeon.

\section{Quality of life}

The median and quartile range for OSA-18 scores at baseline $T 1$ was $64.2(54.7-79.5)$ and postoperatively $T 2$ 


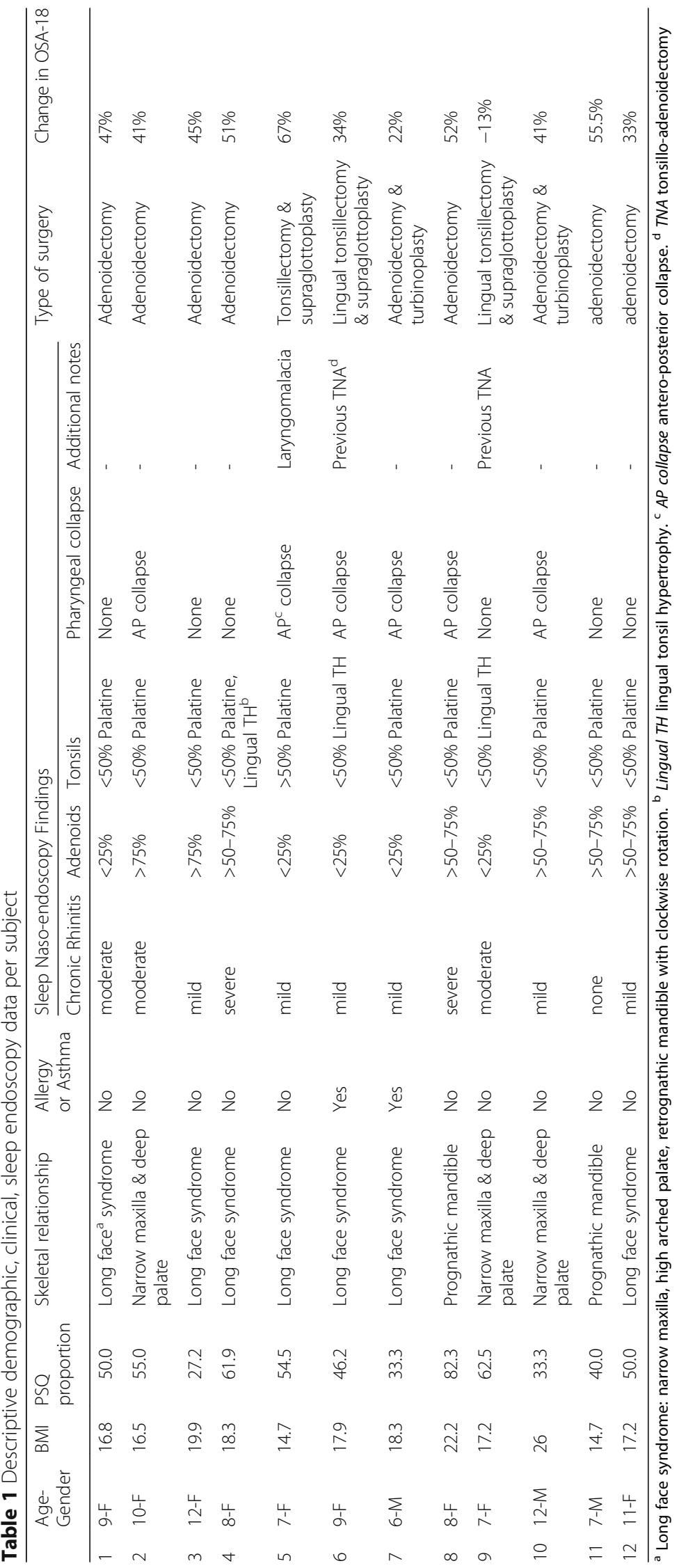


was $37.6(28.7-43)$. The total OSA-18 and sub-domain scores at $\mathrm{T} 1$ and $\mathrm{T} 2$ are summarized in Table 2 . Subject 9 revealed worsening OSA-18 scores and subjects 6 and 7 presented with the smallest improvements in OSA-18 scores, Fig. 1.

\section{Airway measurements}

None of the subjects presented with significant nasal septum deviations. Generally, changes in NS dimensions from $\mathrm{T} 1$ to $\mathrm{T} 2$ were not statistically significant using paired $t$-test, mean volume of the NS was $11.2 \pm 3 \mathrm{~cm}^{3}$ at $\mathrm{T} 1$ and $12.1 \pm 3.1 \mathrm{~cm}^{3}$ at T2 ( $p$-value $\left.=0.07\right)$.

Median changes in conventional and new airway measures specific to the area of surgery, i.e. NP for adenoidectomy and OP for tonsillectomy are presented in Table 3. Overall, the median of all airway measures in the surgical area showed improvement after surgery however with very wide range. Changes in conventional and new airway variables per subject are presented in Fig. 2. Using new airway measures, subjects \#6, 7, and 9 showed small amounts of constriction relief and gain in patency. Subject \#9 had lost airway patency after lingual tonsillectomy by $75 \%$ and subject \#6 had no change in airway patency.

Conventional airway measures show low correlation with quality of life outcome (OSA-18): Spearman Rho $(\rho)=0.37$ for MinXarea, 0.16 for volume, and -0.13 for surface area. Whereas new airway measures show moderate to strong correlation: Spearman $\mathrm{Rho}=0.44$ for constriction and 0.71 for patency. Correlation between OSA-18 and all airway measures is presented in Fig. 3. New airway measures show very strong $(\rho=0.69-0.86)$ and significant correlations with conventional measures such as volume and MinXarea, details in Additional file 1: Table S1.

Part comparison analysis (T2-T1) depicts changes in airway models specific to surgical areas, Fig. 4.

\section{Discussion}

In this clinical pilot, we present the use of 3D models of the upper airways reconstructed from CBCT to assess surgical outcomes in 12 children-adolescents presenting with SDB symptoms and jaw disproportions in the interdisciplinary airway clinic.

All 12 subjects presented with short anterior cranial base, $\mathrm{SN}=60.8 \pm 3.1 \mathrm{~mm}$, similar to a recent study [17] of OSA children (mean age 9) where mean SN was 61.5 $\pm 3.4 \mathrm{~mm}$. Compared to normative data published for 10 year olds mean $\mathrm{SN}=63.9 \pm 2.6 \mathrm{~mm}$ [18] and $70.8 \pm$ $2.9 \mathrm{~mm}$ [19], children with OSA had shorter anterior cranial base lengths, highlighting the interplay between craniofacial form and airway space.

Ideally, full polysomnography (PSG) would be used to diagnose SDB and assess surgical outcome however, it is expensive, time consuming, labor intensive, and very few Canadian institutions can routinely use full PSG. Although sleep pulse oximetry did not rule out SDB (McGill score =1) at baseline, the PSQ-22 scores were over the published cut off $(\geq 0.33)$ [12] for 10 subjects out of 12 indicating high risk of pediatric SDB.

Similar to other studies, the surgical outcomes in this study were assessed using the OSA-18 quality of life questionnaire [13, 20, 21]. Overall, the impact of SDBsymptoms on patients' quality of life reduced after surgery in total OSA-18 score and its subdomains, Table 2. Median total OSA-18 score changed from moderate impact to low. This is based on using the cut off of 60 where total score $<60$ is low, $60-80$ is moderate, and $>80$ is severe impact on quality of life [22]. Several studies reported changes in OSA-18 in children post AT or tonsillectomy, the mean baseline OSA-18 ranged from 61.1 to 77.6 and the range of mean OSA-18 postoperatively was 32.5 to 41 [23-26]. Our cohort presents with similar values at T1 and T2. Subjects 6 and 7 showed the least amount of improvement whereas subject 9 reports worsening of symptoms marked by higher OSA-18 scores in T2 (OSA-18 score was 55 and increased to 62 post-surgically), Fig. 1. After surgery, the parent of subject 9 reports development of swallowing difficulties, aggressive behavior, and difficulties in waking up in the morning. This is a subtle sign of the possible neuro-behavioral and reduced neuromuscular tone contributing factors in the realm of pediatric SDB. Of note, subjects 6 and 9 had lingual tonsillectomies and subjects 6 and 7 were siblings with asthma and allergy.

Table 2 Average scores, median (Q1-Q3), for per- and post-operative OSA-18 questionnaires

\begin{tabular}{|c|c|c|c|c|c|}
\hline & \multirow[t]{2}{*}{$\mathrm{T1}$} & \multirow[t]{2}{*}{$\mathrm{T} 2$} & \multicolumn{2}{|c|}{ Score difference $\mathrm{T} 1-\mathrm{T} 2$} & \multirow[t]{2}{*}{$P$-value ${ }^{a}$} \\
\hline & & & $\mathrm{N}$ & $\%$ & \\
\hline Sleep disturbance & $17(12-22)$ & $8(7.5-10.5)$ & $7.5(4-10.7)$ & $43.4(33.3-61)$ & 0.005 \\
\hline Physical suffering & $16(9.5-17.2)$ & $10(7-11.2)$ & $5(2.3-6.5)$ & $34.8(28.1-48)$ & 0.05 \\
\hline Emotional Distress & $11.5(8.8-14.3)$ & $7.5(4-9.5)$ & $3.5(0.8-6.5)$ & $36.6(6.2-53.1)$ & 0.03 \\
\hline Daytime problems & $9(6.8-16.5)$ & $5.5(4-9.7)$ & $2.5(0.8-7.7)$ & $26.8(15-47.8)$ & 0.05 \\
\hline Caregiver Concern & $14(8.8-19)$ & $5.5(4-8.5)$ & $7(1-11.7)$ & $43.9(20-71.4)$ & 0.005 \\
\hline Total score & $64.2(54.7-79.5)$ & $37.6(28.7-43)$ & $25(14.5-36.5)$ & $40.9(30.3-49.6)$ & $<0.001$ \\
\hline
\end{tabular}

${ }^{a}$ Wilcoxon signed Rank test 


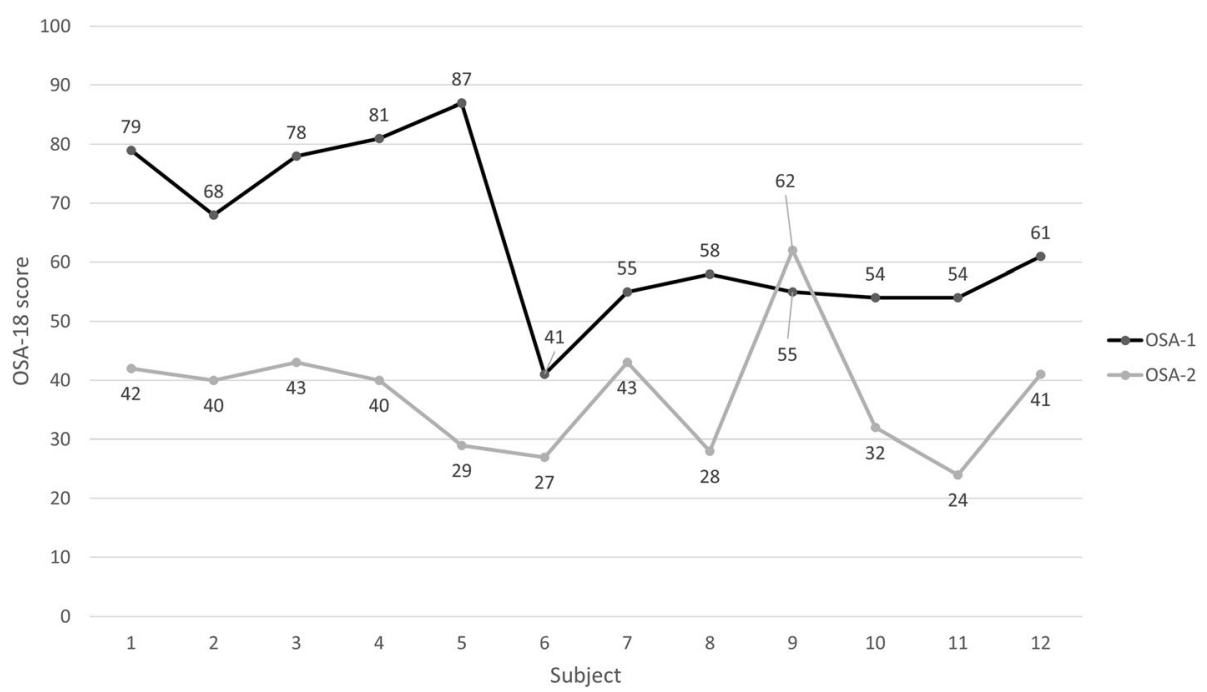

Fig. 1 Scatter plot of OSA-18 scores before and after surgery per subject. Subjects 6 and 7 show smallest improvement whereas subject 9 presents with worsening symptoms

This pilot is the first to utilize 3D models generated from $\mathrm{CBCT}$ to analyze the upper airways pre- and post AT in pediatric SDB. None of the 12 subjects presented with significant nasal septum deviation or nasal constriction. Nose (NS) volume did not change from T1 to T2 even in the two subjects that underwent turbinoplasty (\#6 and 10) possibly due to mucosal thickening at T2.

Overall, there was significant improvement in airway dimensions after surgery in all 12 subjects however with wide range, Table 3 . Subjects 1 and 5 showed the smallest changes in volume and surface area, Fig. 2. Similar to our results, Nandalike et al. [7] reported volume increases in NP (from $2.9 \pm 1.3$ to $4.4 \pm 0.9 \mathrm{~cm}^{3}$ ) and in OP (from $3.2 \pm 1.2$ to $4.3 \pm 2.0 \mathrm{~cm}^{3}$ ). In their study, 27 obese children with OSA underwent PSG and MRI and the volumes of the NP, OP, adenoids, tonsils, and tongue were measured pre and post AT. MinXarea increased for all subjects except for \#6; remained unchanged after surgery. This highlights the deficiency in using MinXarea which focuses on one slice (through the adenoidectomy site) and neglects the entire airway.
Volume and surface area are nonspecific measures because local changes or differences are overlooked. CBCT point-based analysis was previously used to assess postsurgical changes in the craniofacial area [27, 28] and specifically in the upper airway $[10,16]$. Using new airway measures, the mean relief of constriction was $29 \%$ and mean gain of patency by $216.6 \%$, Table 3 . In other words, tissues showing airway lumen narrowing $<4 \mathrm{~mm}$, marking potential sites of collapse, have reduced and areas with over $10 \mathrm{~mm}$ lumen patency have increased post-surgically. This however was not the case in subject 9 showing loss of previous patency by $75 \%$ and unchanged airway patency in subject 6, Fig. 2. Subjects 6 , 7 , and 9 show the least amounts of changes in airway constriction as well as OSA-18, Fig. 2. While airway constriction of subject \#5 modestly improved by $14.3 \%$, there was a large gain airway patency by $150 \%$ after palatine tonsillectomy and presented with the greatest improvement in OSA-18 score by $67 \%$. Subjects 6 and 9 underwent lingual tonsillectomy with history of failed AT and thus already present with complexity in which

Table 3 Average airway measurements specific to the surgical area

\begin{tabular}{|c|c|c|c|c|c|c|}
\hline \multirow[t]{2}{*}{ Airway measure } & \multirow{2}{*}{$\begin{array}{l}\text { T1 Mean } \\
\text { (minimum-maximum) }\end{array}$} & \multirow{2}{*}{$\begin{array}{l}\text { T2 Mean } \\
\text { (minimum-maximum) }\end{array}$} & \multicolumn{3}{|c|}{ \% Score difference T2-T1 } & \multirow[t]{2}{*}{$P$-value } \\
\hline & & & Median (Q1-Q3) & Minimum & Maximum & \\
\hline Volume $\left(\mathrm{cm}^{3}\right)^{c}$ & $4.9(1.8-10.4)$ & $8.4(2.2-18)$ & $42.8(24.8-141.4)$ & 4.6 & 203.3 & 0.002 \\
\hline Surface area $\left(\mathrm{cm}^{2}\right)^{\mathrm{c}}$ & $18.8(1.9-29.3)$ & $22.6(2.7-38)$ & $24(5.2-41.9)$ & -12.3 & 81.8 & 0.02 \\
\hline MinX area $\left(\mathrm{cm}^{2}\right)^{\mathrm{c}}$ & $1.1(0.1-3)$ & $2.7(0.4-3.9)$ & $164.6(109.7-246.2)$ & 0 & 2114.2 & 0.005 \\
\hline Airway constriction <4 mm (\%) & $49(26-92)$ & $32.3(22-68)$ & $29(13.1-46.1)^{a}$ & 7.7 & 64.1 & 0.002 \\
\hline Airway patency >10 mm (\%) & $3.1(0-8)$ & $14(1-31)$ & $216.6(67-774.5)$ & -75 & 1450 & 0.006 \\
\hline
\end{tabular}




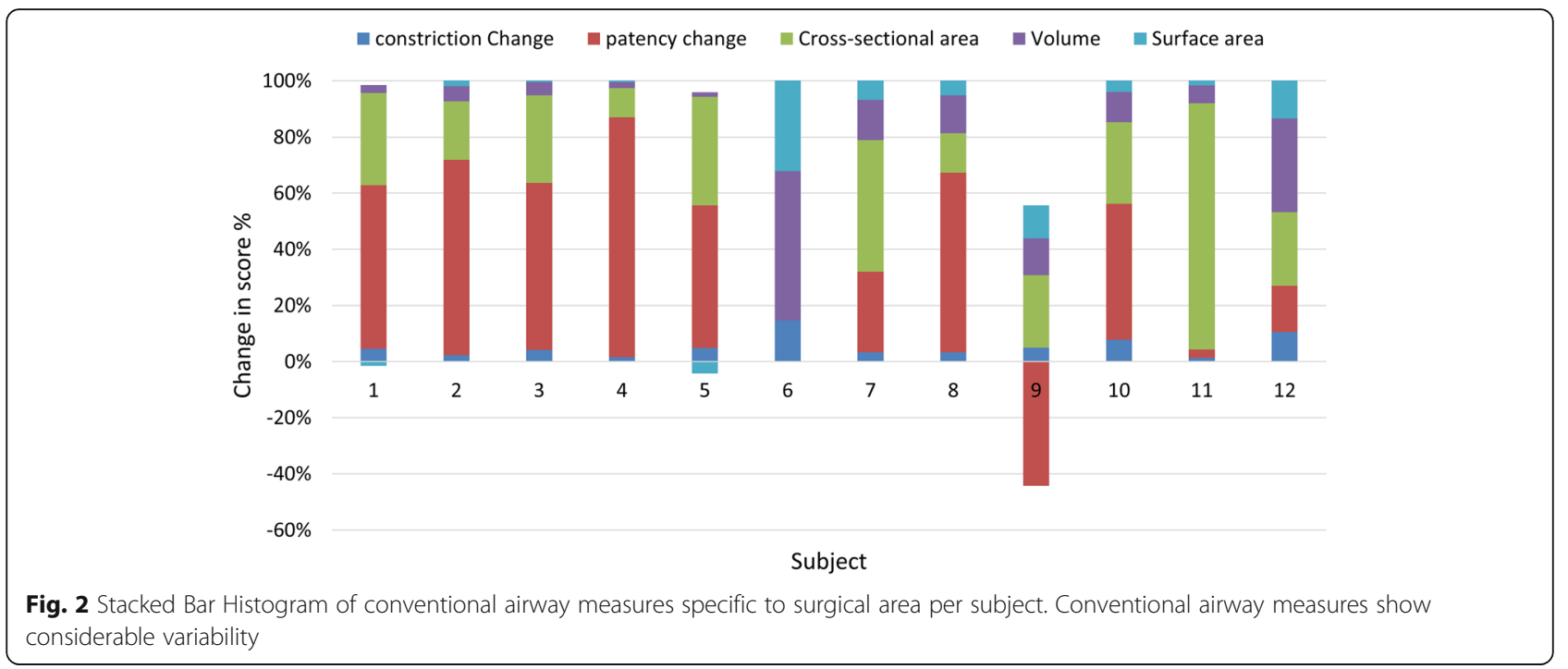

lingual $(\mathrm{T})$ was the last surgical resort. Hypertrophy of the lingual tonsils occurred in one third of children with persistent OSA and along with allergy and asthma present risk factors to residual SDB $[4,29,30]$. Subject 7 underwent (A) and presented with allergy, asthma, and family history of SDB (i.e. subject 6/sibling) all of which are risk factors to residual SDB [29, 30].

It appears that gaining airway patency beyond 150\% and relieving constriction beyond 15\% after surgery did not drastically change scores in the OSA-18; all subjects other than 6, 7, and 9 tend to "plateau" at 40-55\% improvement in OSA-18 post-surgically, Figs. 1 and 2. This is suggestive of a possible threshold of surgical tissue changes beyond which it has low impact on changes in quality of life. This evidently needs to be verified with a larger sample size.

Only new airway parameters, constriction and patency, showed strong correlation with changes in OSA-18

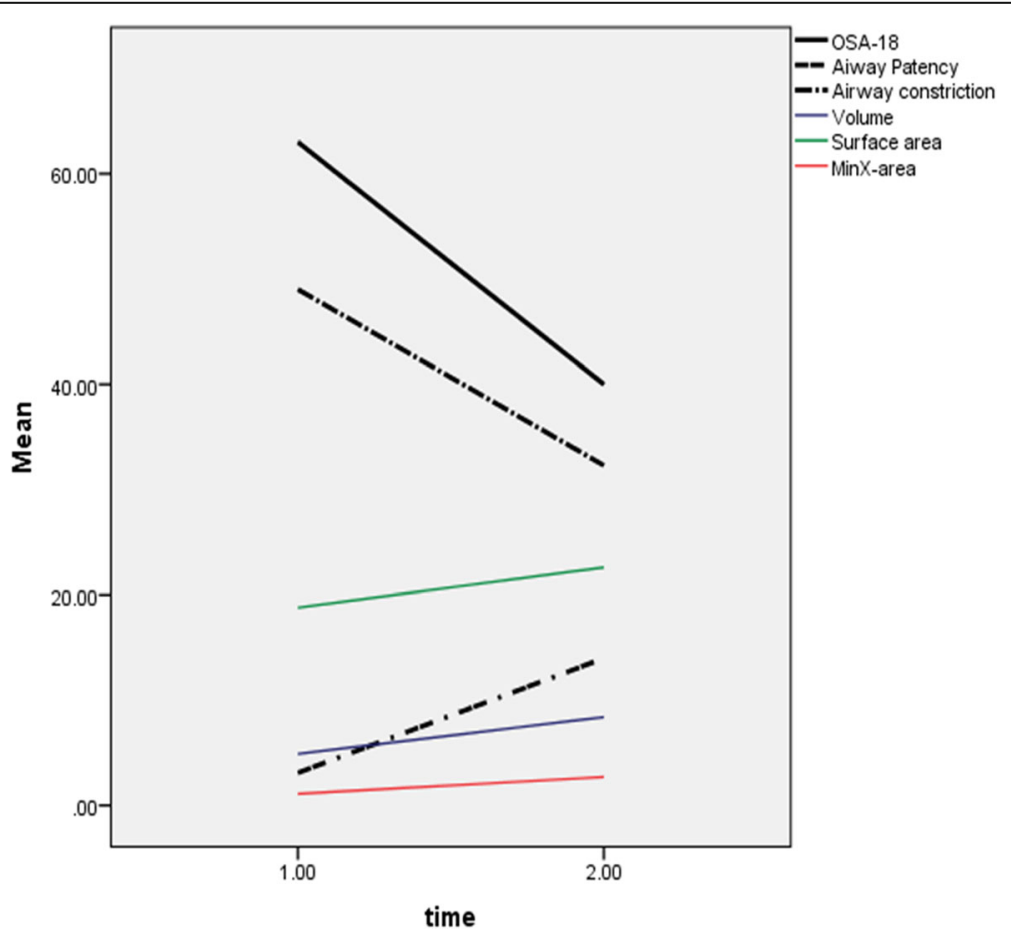

Fig. 3 Line chart of median airway measures and OSA-18 scores at T and T2. The degree of change from T1 to T2 in the median airway constriction and patency is very similar to that of OSA-18 


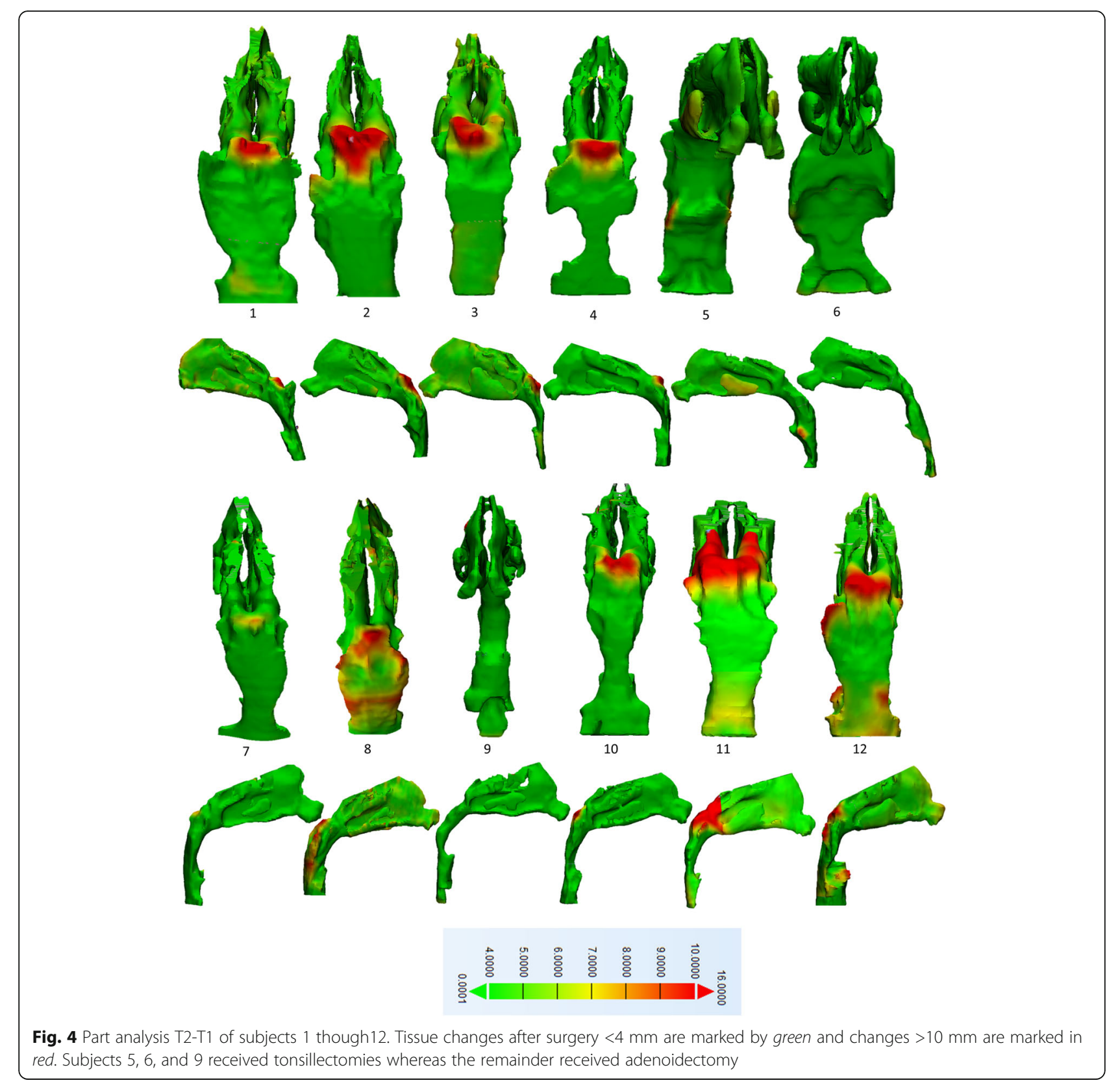

There was moderate correlation between changes in OSA-18 and MinXarea and no-weak correlation with volume and surface area. This suggests that changes in new airway variables better represent the degree of changes in OSA-18 compared to conventional measures, Fig. 3.

When correlating conventional and new airway measures, there was strong correlation confirming that point-based analysis is supplemental to global/conventional measures yet is more explanatory as it takes into account the level (s) of narrowing throughout the entire $3 \mathrm{D}$ object i.e. the airway.

The amount and localization of tissues removed and airway space gained is illustrated in Fig. 4. Changes were more noticeable in adenoidectomy cases and least in subjects 6,7 , and 9 . Overall, $16.5 \%$ of the tissues gained space over $4 \mathrm{~mm}$ in the 12 subjects, and $1.5 \%$ of tissues gained space beyond $10 \mathrm{~mm}$.

Limitations to this pilot are related to the small sample size, heterogeneity of the surgeries included, and existing outliers severely limit options to statistical tests and hinder the $P$-values reported. However, the intention of this level-I diagnostic study was to test feasibility of using new airway measures to assess surgical outcomes.

Future studies with controls and larger sample size will allow rigorous statistical analyses such as regression and discriminant analyses. Ultimately multiple clinical and 
imaging variables can be tested to provide a prediction model.

\section{Conclusions}

This pilot is the first to prospectively evaluate anatomical changes in the upper airways after adenoidectomy or tonsillectomy using accurate 3D airway models from $\mathrm{CBCT}$ with meaningful tools of analysis. In this cohort, it was evident that:

- New airway measures, airway patency and constriction, strongly correlated with quality of life measure (OSA-18) and better explained low scores after surgery.

- Airway patency and constriction also strongly correlated with conventional measures and proved more explanatory.

- Airway patency gained by at least $150 \%$ and constriction relief by at least $15 \%$ showed marked improvement in OSA-18 by $40-55 \%$, after surgery.

\section{Additional file}

Additional file 1: Supplemental Material, Table S1. Correlation between new and traditional airway measures. Figure S1. Sections of the upper airway. Figure S2. Three planes used to section the upper airway models. Figure S3. New airway measures (airway constriction and patency). (DOCX $4915 \mathrm{~kb})$

\section{Abbreviations}

A or T: Adenoidectomy or tonsillectomy; BMl: Body mass index; $\mathrm{CBCT}$ : Cone beam computed tomography; MinXarea: Minimum cross-sectional area; NP: Nasopharynx; NS: Nasal cavity; OP: Oropharynx; OSA: Obstructive sleep apnea; PSG: Polysomnography; PSQ: Pediatric sleep questionnaire; ROI: Region of interest; SDB: Sleep disordered breathing; SN: Sella-Nasion; STL: STereoLithography

\section{Acknowledgements}

N. Alsufyani acknowledges her full PhD sponsorship from King Saud University, Riyadh, Saudi Arabia.

\section{Availability of data and materials}

The datasets generated during and/or analysed during the current study are not publicly available due to ethics approval limits but are available from the corresponding author if approval from the Health Research Ethics Board at the University of Alberta is obtained.

\section{Competing interests}

The authors declare that they have no competing interests.

\section{Consent for publication}

Not applicable.

\section{Ethics approval and consent to participate}

This study was approved by the Health Research Ethics Board at the University of Alberta.

\section{Authors' contributions}

N.A, MN, MW, and PM have made substantial contributions to conception and design, analysis, and interpretation of data; N.A, MN, MW, IC, HE, and PM have been involved in drafting the manuscript or revising it critically for important intellectual content; N.A, MN, MW, IC, HE, and PM had given final approval of the version to be published. N.A, MN, MW, IC, HE, and PM have agreed to be accountable for all aspects of the work in ensuring that questions related to the accuracy or integrity of any part of the work are appropriately investigated and resolved.

\section{Publisher's Note}

Springer Nature remains neutral with regard to jurisdictional claims in published maps and institutional affiliations.

\section{Author details}

${ }^{1}$ School of Dentistry, Faculty of Medicine and Dentistry, University of Alberta, Edmonton, Canada. '2Department of Radiology and Diagnostic Imaging, Faculty of Medicine and Dentistry, University of Alberta, Edmonton, Canada. ${ }^{3}$ Department of Computing Science, Faculty of Science, University of Alberta, Edmonton, Canada. ${ }^{4}$ Department of Surgery, Faculty of Medicine and Dentistry, University of Alberta, Edmonton, Canada. ${ }^{5}$ Edmonton Clinic Health Academy- School of Dentistry, 5th floor, 11405-87 AVE NW, Edmonton T6G $1 C 9, A B$, Canada. ${ }^{6}$ Department of Oral Medicine and Diagnostic Sciences, College of Dentistry, King Saud University, Riyadh, Saudi Arabia.

Received: 14 August 2016 Accepted: 20 March 2017

Published online: 11 April 2017

\section{References}

1. Hatcher DC. Cone Beam Computed Tomography: Craniofacial and Airway Analysis. Dent Clin North Am. 2012;56:343-57.

2. Zettergren-Wijk L, Linder-Aronson S, Nordlander B, Ågren K, Svanborg E. Longitudinal effect on facial growth after tonsillectomy in children with obstructive sleep apnea. World Journal of Orthodontics. 2002;3:67-72.

3. Guilleminault C, Li K, Quo S, Inouye RN. A prospective study on the surgical outcomes of children with sleep-disordered breathing. Sleep. 2004:27:95-100.

4. Schechter MS. Technical report: diagnosis and management of childhood obstructive sleep apnea syndrome. Pediatrics. 2002;109.

5. Costa DJ, Mitchell R. Adenotonsillectomy for obstructive sleep apnea in obese children: A meta-analysis. Otolaryngol Head Neck Surg. 2009;140:455-60.

6. Friedman M, Wilson MN, Pulver TM, Golbin D, Lee GP, Gorelick G, Joseph NJ. Measurements of adult lingual tonsil tissue in health and disease. Otolaryngol Head Neck Surg. 2010;142:520-5.

7. Nandalike K, Shifteh K, Sin S, Strauss T, Stakofsky A, Gonik N, Bent J, Parikh SR, Bassila M, Nikova M, Muzumdar H, Arens R. Adenotonsillectomy in obese children with obstructive sleep apnea syndrome: Magnetic resonance imaging findings and considerations. Sleep. 2013;36:841-7.

8. Alsufyani NA, Al-Saleh MA, Major PW. CBCT assessment of upper airway changes and treatment outcomes of obstructive sleep apnoea: a systematic review. Sleep Breath. 2013;17:911-23.

9. Alsufyani NA, Flores-Mir C, Major PW. Three-dimensional segmentation of the upper airway using cone beam CT: A systematic review. Dentomaxillofacial Radiology. 2012;41:276-84.

10. Alsufyani NA, Hess A, Noga M, Ray N, Al-Saleh MAQ, Lagravère MO, Major PW. New algorithm for semiautomatic segmentation of nasal cavity and pharyngeal airway in comparison with manual segmentation using conebeam computed tomography. Am J Orthod Dentofacial Orthop. 2016;150: 703-12.

11. Slaats MA, Van Hoorenbeeck K, Van Eyck A, Vos WG, De Backer JW Boudewyns A, De Backer W, Verhulst SL. Upper airway imaging in pediatric obstructive sleep apnea syndrome. Sleep Med Rev. 2014;21:59-71.

12. Chervin RD, Hedger K, Dillon JE, Pituch KJ. Pediatric sleep questionnaire (PSQ): Validity and reliability of scales for sleep-disordered breathing, snoring, sleepiness, and behavioral problems. Sleep Med. 2000;1:21-32.

13. Mitchell RB, Garetz S, Moore RH, Rosen CL, Marcus CL, Katz ES, Arens R, Chervin RD, Paruthi S, Amin R, Elden L, Ellenberg SS, Redline S. The use of clinical parameters to predict obstructive sleep apnea syndrome severity in children: The Childhood Adenotonsillectomy (CHAT) study randomized clinical trial. JAMA Otolaryngology - Head and Neck Surgery. 2015;141:130-6.

14. Nixon GM, Kermack AS, Davis GM, Manoukian JJ, Brown KA, Brouillette RT. Planning adenotonsillectomy in children with obstructive sleep apnea: the role of overnight oximetry. Pediatrics. 2004;113:e19-25.

15. Horwood L, Brouillette RT, McGregor CD, Manoukian JJ, Constantin E. Testing for pediatric obstructive sleep apnea when health care resources are rationed. JAMA Otolaryngol Head Neck Surg. 2014;140:616-23. 
16. Alsufyani NA, Dietrich NH, Lagravère MO, Carey JP, Major PW. Cone beam computed tomography registration for 3-D airway analysis based on anatomic landmarks. Oral Surgery, Oral Medicine, Oral Pathology and Oral Radiology. 2014;118:371-83.

17. Korayem MM, Witmans M, MacLean J, Heo G, El-Hakim H, Flores-Mir C, Major PW. Craniofacial morphology in pediatric patients with persistent obstructive sleep apnea with or without positive airway pressure therapy: A cross-sectional cephalometric comparison with controls. Am J Orthod Dentofac Orthop. 2013;144:78-85.

18. Obloj B, Fudalej P, Dudkiewicz Z. Cephalometric standards for polish 10year-olds with normal occlusion. Angle Orthod. 2008;78:262-9.

19. Thilander B, Persson M, Adolfsson U. Roentgen-cephalometric standards for a Swedish population. A longitudinal study between the ages of 5 and 31 years. Eur J Orthod. 2005;27:370-89.

20. Friedman M, Samuelson CG, Hamilton C, Maley A, Taylor D, Kelley K Pearson-Chauhan K, Hoehne C, Levay AJ, Venkatesan TK. Modified adenotonsillectomy to improve cure rates for pediatric obstructive sleep apnea: A randomized controlled trial. Otolaryngology - Head and Neck Surgery (United States). 2012;147:132-8.

21. Tripuraneni M, Paruthi S, Armbrecht ES, Mitchell RB. Obstructive sleep apnea in children. Laryngoscope. 2013;123:1289-93.

22. Franco Jr RA, Rosenfeld RM, Rao M. Quality of life for children with obstructive sleep apnea. Otolaryngol Head Neck Surg. 2000;123:9-16.

23. Kobayashi R, Miyazaki S, Karaki M, Hoshikawa H, Nakata S, Hara H, Kodama S, Kikuchi A, Kitamura T, Mori N. Evaluation of adenotonsillectomy and tonsillectomy for pediatric obstructive sleep apnea by rhinomanometry and the OSA-18 questionnaire. Acta Otolaryngol. 2014;134:818-23.

24. Lee C, Kang K, Weng W, Lee P, Hsu W. Quality of life after adenotonsillectomy in children with obstructive sleep apnea: Short-term and long-term results. Int J Pediatr Otorhinolaryngol. 2015;79:210-5.

25. Mitchell RB, Kelly J. Quality of life after adenotonsillectomy for SDB in children. Otolaryngol Head Neck Surg. 2005;133:569-72.

26. Ye J, Liu H, Zhang G, Li P, Yang Q, Liu X, Li Y. Outcome of adenotonsillectomy for obstructive sleep apnea syndrome in children. Ann Otol Rhinol Laryngol. 2010;119:506-13.

27. Cevidanes LHC, Oliveira AEF, Grauer D, Styner M, Proffit WR. Clinical Application of 3D Imaging for Assessment of Treatment Outcomes. Semin Orthod. 2011;17:72-80

28. Cevidanes LHC, Heymann G, Cornelis MA, DeClerck HJ, Tulloch JFC. Superimposition of 3-dimensional cone-beam computed tomography models of growing patients. Am J Orthod Dentofac Orthop. 2009;136:94-9.

29. Bhattacharjee R, Kheirandish-Gozal L, Spruyt K, Mitchell RB, Promchiarak J, Simakajornboon N, Kaditis AG, Splaingard D, Splaingard M, Brooks LJ, Marcus CL, Sin S, Arens R, Verhulst SL, Gozal D. Adenotonsillectomy outcomes in treatment of obstructive sleep apnea in children: A multicenter retrospective study. Am J Respir Crit Care Med. 2010;182:676-83.

30. Tauman R, Gulliver TE, Krishna J, Montgomery-Downs HE, O'Brien LM, Ivanenko A, Gozal D. Persistence of obstructive sleep apnea syndrome in children after adenotonsillectomy. J Pediatr. 2006;149:803-8.

\section{Submit your next manuscript to BioMed Central and we will help you at every step:}

- We accept pre-submission inquiries

- Our selector tool helps you to find the most relevant journal

- We provide round the clock customer support

- Convenient online submission

- Thorough peer review

- Inclusion in PubMed and all major indexing services

- Maximum visibility for your research

Submit your manuscript at www.biomedcentral.com/submit

) Biomed Central 